\title{
O potencial transformador da arte: um diálogo entre Vigotski e Antonio Candido ${ }^{1}$
}

\author{
The transformational potential of art: a Vigotski and Antonio Candido
}

dialogue

\begin{abstract}
Denise Stefanoni Combinato
Doutora em Saúde Coletiva pela Faculdade de Medicina de Botucatu/Universidade Estadual Paulista. Psicóloga e professora do Departamento de Humanidades do Instituto Tecnológico de Aeronáutica, São José dos Campos, SP - Brasil denisecombinato@hotmail.com
\end{abstract}

"Livros não mudam o mundo, quem muda o mundo são as pessoas.

Os livros só mudam as pessoas."

Mário Quintana

Resumo: Este artigo faz uma reflexão sobre o potencial transformador que a arte, especificamente a literatura e o audiovisual, tem na Educação. Essa reflexão é resultado de um trabalho de pesquisa realizado em uma Escola Estadual de Ensino Médio Integral do Estado de São Paulo, que tem como objetivo investigar se há e quais são os impactos da articulação entre a arte literária e o audiovisual no processo ensino-aprendizagem. Tal reflexão fundamenta-se na Psicologia histórico-cultural e na leitura de duas obras principais: "Psicologia da Arte", de Lev Vigotski (1999) e "O direito à literatura", de Antonio Candido (1988). Entende-se que esse potencial de transformação da arte relaciona-se com o processo de humanização, que envolve a apropriação e a confirmação das características tipicamente humanas.

Palavras-chave: Arte. Literatura. Audiovisual. Educação. Humanização.

Abstract: This article presents a reflection on art's, specifically literature and audiovisuals, transformational potential on Education. This reflection results from a research carried out in a São Paulo State full period high school, aimed to investigate if there are and which are the impacts of literature and audiovisual articulation on the teaching-learning process. Such reflection is grounded on the Socio-historical Psychology and two major books: "Art Psychology" by Lev Vigotski (1999) and "The right to literature" by Antonio Candido (1988). The understanding is that art's transformative potential is related to the humanization process, which involves the appropriation and confirmation of the human typical characteristics.

Keywords: Art. Literature. Audiovisual. Education. Humanization. 


\section{Introdução}

Os livros mudam as pessoas, que mudam o mundo, que muda as pessoas, que mudam...

Por que mudar o mundo e as pessoas? O que mudar no mundo e nas pessoas?

Trataremos aqui de uma única mudança que relaciona mundo e pessoas: a mudança de um ser "candidato à humanidade" (Piéron, s/d, in LEONTIEV, 1978, p.255), regido pelas leis biológicas, para um ser humano regido pelas leis histórico-culturais. Isso significa a mudança de uma condição passiva de adaptação à realidade externa para uma relação ativa e consciente com a realidade, que vise à produção dos meios de sobrevivência.

Essa mudança depende da apropriação daquilo que o gênero humano ${ }^{2}$ já acumulou e produziu historicamente: "para que os indivíduos se insiram na história, humanizando-se, eles precisam de educação, da transmissão da cultura material e simbólica por parte de outros indivíduos" (MARTINS, 2013, p.10). Ou seja, o "mundo", através da educação escolar, precisa disponibilizar essa cultura para que as "pessoas", numa condição ativa, apropriem-se dela e desenvolvam as funções tipicamente humanas.

De acordo com Saviani (1992), "o trabalho educativo é o ato de produzir, direta e intencionalmente, em cada indivíduo singular, a humanidade que é produzida histórica e coletivamente pelo conjunto dos homens" (p. 21). Isso significa que, através do trabalho educativo, o aluno deve apropriar-se dos elementos culturais desenvolvidos ao longo da história para tornar-se humano. A escola é o espaço privilegiado de organização e disseminação desse saber sistematizado, sendo responsável, assim, por disponibilizar essa cultura para formar o ser humano.

Para tanto, não basta assimilar um conhecimento técnico-instrumental; é preciso garantir o acesso aos conhecimentos clássicos, ir além das necessidades básicas de sobrevivência e atingir as necessidades históricas.

A arte é uma dessas necessidades. Candido (1988) defende que não se pode negar aos homens o acesso aos "bens incompressíveis", sob pena de "desorganização pessoal" ou "frustração mutiladora" (p. 174). Segundo o autor, esses bens não são apenas aqueles que asseguram a integridade física como, por exemplo, alimentação, moradia e saúde, mas também aqueles que garantem a integridade espiritual como liberdade, justiça, direito à crença e à opinião, lazer.

Alguns argumentos utilizados por Candido (1988) na defesa de que a arte e a literatura estão nessa categoria (de bens incompressíveis) são: a literatura é uma "manifestação 
universal de todos os homens em todos os tempos" (p.174) e "ninguém é capaz de passar as vinte e quatro horas do dia sem alguns momentos de entrega ao universo fabuloso" (p.174). Ora, se não passamos um dia sequer sem recorrer ao devaneio, então a arte corresponde, de fato, a uma necessidade básica.

Numa perspectiva histórico-cultural, podemos dizer que essas necessidades espirituais estão relacionadas ao processo de humanização, ou seja, ao processo de desenvolvimento do gênero humano, em outras palavras, o desenvolvimento de características tipicamente humanas constituídas ao longo da história da humanidade como, por exemplo, a linguagem, o pensamento e a imaginação, funções tipicamente humanas denominadas de funções psíquicas superiores.

Se a arte é um patrimônio cultural da humanidade e promove o desenvolvimento das funções tipicamente humanas, concordamos com Candido (1988) que elas devem ser entendidas como bens incompressíveis e de acesso a todas as pessoas, sendo a educação escolar responsável pela socialização daquilo que é "clássico", "fundamental", "essencial" (SAVIANI, 1992, p. 21), ou seja, daquilo que "resistiu ao tempo" (p.25), pois "expressa as leis que regem a existência de determinado fenômeno, [...] algo cuja validade é universal" e que "se aplica tanto a fenômenos naturais como sociais" (p.63).

Concluída essa explanação sobre a necessidade de o mundo (com foco aqui na educação escolar) promover o conhecimento às pessoas (inclusive o conhecimento da arte), tendo em vista a transformação das pessoas e do mundo, discutiremos, com base em Vigotski (1999) e Antonio Candido (1988), três características da arte que foram objeto de discussão de um grupo de pesquisadores em uma Escola Estadual de Ensino Médio Integral do Estado de São Paulo: a arte como mediação da cultura; o papel da forma nas obras de arte; e o efeito produzido por elas no sujeito.

\section{Contextualização}

Desde fevereiro de 2017, está sendo desenvolvida uma pesquisa em uma Escola Estadual de Ensino Médio Integral do Estado de São Paulo, com auxílio da Fundação de Amparo à Pesquisa do Estado de São Paulo (FAPESP), cujo objetivo é investigar se há e quais são os impactos da articulação entre a arte literária e o audiovisual no processo ensinoaprendizagem. 
A pesquisa fundamenta-se nos princípios teórico-metodológicos da Psicologia histórico-cultural e o método utilizado é o da pesquisa-ação, caracterizado pela inter-relação entre intervenção (ensino) e produção do conhecimento (pesquisa).

Essa pesquisa envolve duas atividades paralelas e interligadas: 1) a pesquisa-ação com os alunos do Ensino Médio; e 2) o planejamento e a avaliação das atividades de pesquisaação, assim como a formação/capacitação do grupo de pesquisadores constituído por professores e gestores da Educação Básica e pesquisadores externos.

Em relação à pesquisa-ação com os alunos, estão sendo acompanhadas três turmas de alunos que iniciaram o $1^{\circ}$ ano do Ensino Médio em 2017 e encerrarão esse ciclo em 2019. Em cada bimestre, a partir de uma temática previamente estabelecida pelo corpo docente para o semestre ou para o ano, é desenvolvida uma atividade curricular interdisciplinar que articula literatura e audiovisual.

No final de 2017, concluíram o ano letivo nessa escola 356 alunos, sendo 100 alunos concluintes do $1^{\circ}$ ano do Ensino Médio, 137 alunos do $2^{\circ}$ ano e 119 alunos do $3^{\circ}$ ano.

Para a realização do trabalho pedagógico com esses alunos, em 2017 essa escola contava com três membros na equipe gestora (direção e coordenação pedagógica) e 20 professores, sendo uma professora responsável pela Sala de Leitura e três professores acumulando também as coordenações de áreas (Ciências da Natureza e suas Tecnologias; Ciências Humanas e suas Tecnologias; Linguagem, Códigos e suas Tecnologias).

Em relação às atividades de planejamento e avaliação da pesquisa-ação, e formação/capacitação do grupo de pesquisadores, são realizadas discussões teóricometodológicas e vivências sobre a arte, incluindo leitura e discussão de textos e livros teóricotécnicos; leitura e discussão de textos literários; exibição e discussão de curtas e documentários, com objetivo de auxiliar na qualificação da prática profissional dos pesquisadores e subsidiar o desenvolvimento da pesquisa-ação com os alunos.

Em 2017, esse grupo foi composto por professores (seis professoras, sendo três contempladas com bolsa de aprimoramento pedagógico da FAPESP) e gestores (diretora e coordenadora pedagógica) da Escola Estadual, além de três pesquisadoras externas, sendo duas pesquisadoras voluntárias e uma pesquisadora vinculada à Instituição de Ensino Superior, responsável por essa pesquisa.

Foram realizadas, de fevereiro a dezembro de 2017, 25 reuniões com o grupo de pesquisadores, com duração de uma hora e 40 minutos cada.

A reflexão sobre o potencial transformador da arte que esse artigo pretende abordar é fruto principalmente do trabalho desenvolvido com esse grupo de pesquisadores na escola. 


\section{A arte como mediação da cultura}

Vigotski (1999) afirma, em concordância com Guyeau, que a arte é uma "condensação da realidade" (p.315) e Antonio Candido (1988) caracteriza a literatura também como uma "forma de conhecimento" (p.176). Isso não significa que a arte seja uma reprodução da realidade, mas uma criação a partir da realidade. Um exemplo dado por Vigotski (1999) a esse respeito articula vida e arte a um milagre do Evangelho, a transformação da água em vinho: "a arte está para a vida como o vinho para a uva [...] a arte recolhe da vida o seu material mas produz acima desse material algo que ainda não está nas propriedades desse material” (p.307-308).

Em uma das reuniões do grupo de pesquisadores, assistimos a alguns trechos do documentário “O povo brasileiro", de Isa Grinspum Ferraz (2000), realizado a partir da obra de Darcy Ribeiro, "O povo brasileiro: a formação e o sentido do Brasil”" (1995). O documentário discute a formação do povo brasileiro, com destaque para as matrizes indígena, luso e africana. São apresentados aspectos de cada cultura que resultaram na miscigenação do povo brasileiro. O documentário contou com a participação, dentre outros, de Darcy Ribeiro, Chico Buarque, Gilberto Gil, Tom Zé e Antonio Candido.

Algumas manifestações das professoras, após a exibição do documentário, foram: "Você se vê ali [...] isso sou eu"; "Leva a gente para uma realidade de forma poética"; "Redescobrir-me como brasileira não tem preço!”.

A arte possibilita, além do conhecimento da realidade, um "redescobrir-se", uma vez que mobiliza "a subjetividade para muito além da cotidianidade, num movimento em direção tanto ao núcleo da própria personalidade como da realidade social” (DUARTE et al., 2012, p. 36).

Daí a importância de promover o acesso às obras literárias e audiovisuais aos professores em espaços de formação docente. O primeiro obstáculo para acessar os níveis eruditos, de acordo com Candido (1988), não é a incapacidade, mas a oportunidade. Exceto a professora de História, que foi quem indicou o documentário, as outras não demonstraram conhecê-lo. A exibição e a discussão mobilizaram o grupo para o conhecimento do documentário na íntegra e para a exibição aos alunos.

Vigotski (1999) também afirma que "a arte é o social em nós" (p. 315), o que significa que tanto a apropriação da arte como a objetivação de emoções e sentimentos em um objeto artístico envolvem uma apropriação social, uma mediação cultural. Podemos dizer que a arte caracteriza-se por uma "unidade dialética entre a singularidade e a universalidade, entre a 
objetividade e a subjetividade" (DUARTE, 2009, p.469), em um movimento de humanização. Assumpção e Duarte (2015) explicam que "a arte - seja na recepção ou na criação - possibilita aos indivíduos entrarem em contato com sentimentos que ultrapassam as experiências pessoais e se aproxima do gênero humano" (p.240).

\section{O papel da forma nas obras de arte}

De acordo com Candido (1988), "o conteúdo só atua por causa da forma”, ou seja, "a mensagem é inseparável do código, mas o código é a condição que assegura o seu efeito" (p.178).

Vigotski (1999) também defende a importância da forma na constituição da obra. Para o autor, é a contradição entre o conteúdo e a forma que produz a reação estética:

[...] durante séculos os especialistas em estética vêm afirmando a harmonia da forma e do conteúdo, dizendo que a forma ilustra, completa, acompanha o conteúdo, e de repente descobrimos que isto é o maior dos equívocos, que a forma combate o conteúdo, luta com ele, supera-o, e que nessa contradição dialética entre conteúdo e forma parece resumir-se o verdadeiro sentido psicológico da nossa reação estética (p. 199).

Após a leitura do texto "O direito à literatura", de Antonio Candido (1988) com o grupo de pesquisadores, e a discussão de que a literatura "humaniza em sentido profundo porque faz viver" (p. 176), uma professora relatou que sentia sede quando lera o livro "Vidas Secas", de Graciliano Ramos.

Qual o motivo de a professora ter sentido sede ao ler "Vidas Secas"? Será o conteúdo da obra? Será que um texto jornalístico que trate da seca no nordeste produziria o mesmo efeito?

De acordo com esses autores, não é o conteúdo ou puramente o conteúdo ou o conteúdo dissociado da forma que produz esse efeito; é a forma, a maneira como a obra de arte é elaborada e articulada ao conteúdo, que tem um papel fundamental.

\section{$O$ efeito da arte}

Partindo da realidade, mas não nos restringindo a ela; e com uma construção estética elaborada entre forma e conteúdo; a obra de arte, numa analogia à transformação da água em vinho, também provoca a transformação do ser humano como nos indica Vigotski (1999): 
[...] a verdadeira natureza da arte sempre implica algo que transforma, que supera o sentimento comum, e aquele mesmo medo, aquela mesma dor, aquela mesma inquietação, quando suscitadas pela arte, implicam o algo a mais acima daquilo que nelas está contido (p.307).

Essa transformação das emoções provocada pela arte é a catarse. Para o autor,

[...] toda obra de arte [...] encerra forçosamente uma contradição emocional, suscita séries de sentimentos opostos entre si e provoca seu curto-circuito e destruição. A isto podemos chamar o verdadeiro efeito da obra de arte, e com isto nos aproximamos em cheio do conceito de catarse (VIGOTSKI, 1999, p.269).

Consonante a essa visão, Candido (1988) afirma que a palavra organizada promove a organização dos sentimentos e pensamentos:

[...] o caráter de coisa organizada da obra literária torna-se um fator que nos deixa mais capazes de ordenar a nossa própria mente e sentimentos; e, em consequência, mais capazes de organizar a visão que temos do mundo (p. 177).

Apresentamos na sessão anterior o relato de uma professora que sentia sede ao ler "Vidas Secas". Outra professora, que afirmava que antes de participar do grupo de pesquisadores entendia a literatura como algo "separado da vida [...] e da relação com a sociedade", leu "Vidas Secas" após presenciar o relato da colega.

Essa professora afirmou que teve uma boa formação acadêmica, em um modelo tradicional, mas não teve uma formação estética e expressiva ao longo dos seus estudos. Por isso, frequentemente, valorizava o espaço de formação desse grupo, seja como subsídio necessário para a condução da pesquisa-ação, seja como aperfeiçoamento profissional e pessoal.

Em outro momento, essa professora, que afirmou ter descoberto a literatura no grupo de pesquisadores, relatou que leu um trecho de "Vidas Secas" aos seus alunos "para que eles pudessem sentir [...] sem estar no local", como uma forma de mobilizar o interesse deles pela literatura e o conhecimento da cultura pela literatura. Ela contou aos alunos sobre sua experiência com o livro. Disse que antes da leitura de "Vidas Secas", "sabia, mas não sentia", ou seja, ela sabia da condição da seca no nordeste brasileiro, em função da formação acadêmica, mas sentiu essa condição com a obra literária. Vários alunos manifestaram interesse e leram essa obra. 


\section{Considerações finais}

Buscamos abordar neste artigo o potencial de transformação da arte a partir da discussão trazida principalmente por dois autores, Vigotski e Antonio Candido, articulando essa discussão ao trabalho de pesquisa em desenvolvimento em uma Escola Pública de Ensino Médio Integral, com foco no trabalho realizado com o grupo de pesquisadores.

Os principais aspectos abordados pelo artigo foram: a arte como mediação da cultura, ou seja, a arte como forma de apropriação da realidade e de conhecimento; a composição da arte, integrando conteúdo e forma, com destaque para a interferência da forma no conteúdo para a produção da obra de arte; e, por fim, o efeito que a arte provoca no ser humano, em função da elaboração psíquica exigida a partir da contradição emocional desencadeada pela vivência da obra.

Entende-se que o potencial de transformação da arte relaciona-se com o processo de humanização na medida em que proporciona o acesso à produção historicamente acumulada e o desenvolvimento de funções psíquicas superiores ou a confirmação de traços essenciais ao ser humano como:

[...] o exercício da reflexão, a aquisição do saber, a boa disposição para com o próximo, o afinamento das emoções, a capacidade de penetrar nos problemas da vida, o senso da beleza, a percepção da complexidade do mundo e dos seres, o cultivo do humor (CANDIDO, 1988, p.180).

A leitura da obra "Vidas Secas", por exemplo, como consequência da participação em um grupo de pesquisadores que integra professores e gestores da Educação Básica com pesquisadores externos, parece ter provocado uma transformação em uma professora e, possivelmente, nos alunos com os quais trabalhou. Saber sem sentir é diferente de sentir mesmo distante de tempo e espaço. O acesso a essa obra parece ter transformado a sua relação com esse conhecimento, talvez ampliando sua compreensão da realidade, de si e do outro,

Os livros mudam as pessoas, que mudam o mundo, que muda as pessoas, que mudam...

\section{Notas explicativas}

1. Apoio: Fundação de Amparo à Pesquisa do Estado de São Paulo (FAPESP), processo no 2014/50841-4.

2. Gênero humano diz respeito ao processo de apropriação / objetivação das características humanas criadas socialmente ao longo da história. Nas palavras de Saviani (1992), refere-se à “formação da humanidade em cada indivíduo singular" (p.30). 


\section{Referências}

ASSUMPÇÃO, M. C.; DUARTE, N. A arte e o ensino de literatura na educação escolar.

Contexto, n.27, p.238-258, 2015. Disponível em: http://www.periodicos.ufes.br/contexto/article/view/10422/7354 Acesso em: 30 jan 2018.

CANDIDO, A. O direito à literatura. In: Vários escritos. 3. ed. São Paulo: Duas cidades, 1988. p. 169-191.

DUARTE, N. Arte e educação contra o fetichismo generalizado na sociabilidade contemporânea. Perspectiva, v.27, n.2, p.461-479, 2009. Disponível em: https://periodicos.ufsc.br/index.php/perspectiva/article/download/2175.../15289 Acesso em: 31 jan 2018.

DUARTE, N. et al. O ensino da recepção estético-literária e a formação humana. Eccos Rev. Cient., n.28, p.31-48, 2012. Disponível em: <http://www.redalyc.org/pdf/715/71523339003.pdf>. Acesso em: 31 jan. 2018.

LEONTIEV, A. O desenvolvimento do psiquismo. Tradução de M. D. Duarte. Lisboa: Livros Horizonte, 1978.

MARTINS, L. M. O desenvolvimento do psiquismo e a educação escolar: contribuições à luz da psicologia histórico-cultural e da pedagogia histórico-crítica. Campinas/SP: Autores Associados, 2013.

O POVO brasileiro. Direção de Isa Grinspum Ferraz. São Paulo: Fundação Darcy Ribeiro, TV Cultura e GNT, 2000. 2 DVD (280 min).

SAVIANI, D. Pedagogia histórico-crítica: primeiras aproximações. 3. ed. São Paulo: Cortez; Autores Associados, 1992.

VIGOTSKI, L. S. Psicologia da arte. Tradução de P. Bezerra. São Paulo: Martins Fontes. 1999. 
recebido em 02 fev. 2018 / aprovado em 01 out. 2018

Para referenciar este texto:

COMBINATO, D. S. O potencial transformador da arte: um diálogo entre Vigotski e Antonio Candido. Dialogia, São Paulo, n. 30, p. 101-110, set. /dez. 2018. Disponível em: $<$ https://doi.org/10.5585/Dialogia.n30.8328 